\title{
Chapter 8 \\ The Dialectic Dynamics of Same <> \\ Non-Same and Human Development
}

In addition to the role of visible $<>$ invisible tension, the discussion in "Reunion with Others: Foundations of the Presentational Self in Daily Lives" also suggested that the meaning construction discussed in this monograph is essentially a regulation of same $<>$ non-same tension concerning children. Previously, we observed young children telling detailed stories of their experiences to their mothers, and elementary school children writing the details of their interactions in nikki journals addressed to their teachers. Now I will consider these children's works in the construction of their sameness and non-sameness, both for others and themselves.

This tension is ubiquitous in children's lives. In the flow of irreversible time, children are considered basically the same person by the adults around them. However, their meaning construction sometimes constructs a detailed presentation that elaborates the non-sameness that they achieve in their lives, in contrast with the illusion of sameness that others have of them. This understanding shows that development is never a phenomenon presented via the change of several indices, but rather what occurs in the fluctuation based on the preservation of sameness and the emergence of non-sameness. In this fluctuation, constructing a model to predict the occurrence of a certain meaning construction is difficult; what I was able to do was discover several characteristic episodes within a large volume of qualitative data to illustrate what possibly happens. Moreover, these meaning constructions are achieved at the microgenetic level, and may have no direct effect on development at the ontogenetic level.

This difficulty of prediction concerning meaning construction also indicates the need to understand the same $<>$ non-same tension that is at the foundation of our development. Although many of us very naturally believe that our material or social environments are stable, we constantly inhabit the non-sameness of them. In this process, non-sameness is not only the result of development, but also a ground that leads to further development. Thus, to elaborate the nature of development I have pursued through this monograph a little further, here I will add a very short discussion concerning the dynamics of same $<>$ non-same tension, which has already been pointed out by the founders of developmental psychology. 


\section{The Dialectic Tension Concerning Sameness as Ubiquitous Dynamics}

In our daily lives, we presuppose the sameness of our environment and of ourselves as the foundation of our conduct. We ordinarily understand that we live in the same house as yesterday, sleep in the same bed, and meet with the same family members. On this understanding, we also assume the stability of our selves, which plays an important role in our lives. In this way, our construction of the sameness of ourselves and our environment works with our belief in the existence of the invisible future (Chap. 7) to validate our roles in society.

Conversely, when we focus on the microgenetic aspects of our conduct, both ourselves and our environments are not exactly the same as they were even 1 second ago. For example, when we spend time in our house, we are often moving inside the house and physically not in the same position. Even when we watch TV on the couch, our eyes move to follow the movements onscreen. This can be generalized as "in the movement between being in the current setting and striving out of that very same setting" (Valsiner, 2007, p. 127). The setting itself is also constantly on the move. For example, the house we live in seems to look the same at all times, but sunlight from the windows is always moving, gradually changing the view inside the room. Thus, we construct a stable world and stable selves despite the fact that almost everything is constantly changing. In other words, our environments have similarity, not the exact sameness.

This presupposition of the sameness of people and environments also applies to studies of developmental psychology. Although many describe the changes in our actions (i.e., performance in a given task) along the flow of time, this does not assume that the person became a totally different person. These studies also rely on the sameness of the tasks or questions used in the data collection. The developmental or inter-individual differences among reactions are discussed in relation to tasks understood as remaining the same during multiple uses of them by the researchers, and the sameness of the people who gave these performances. In this way, change is often understood only in relation to sameness.

Considering these dynamics, the processes of meaning construction analyzed in the former chapters are the microgenesis that competes with the construction of the sameness. As I discussed in Chap. 6, these processes are closely related to participants' recognition of the sameness of themselves in reunion. However, this recognition exists in relation to non-sameness: that is, the conversation or writings concerning children's experiences describe what makes them different from before. Thus, the presentational self is what appears in the area of similarity constructed by children and their relationships with their environments. 


\section{Focus on the Repetition and Its Amplitude}

Though it is difficult to predict precisely what will happen in these dynamics (Chap. 6), the concept of similarity gives us access to the nature of development at the microgenetic level. In discussing pragmatics, Sovran (1992) focused on the relationship between similarity and sameness, suggesting that many subtypes of similarity, denoted by the various ways of description (e.g., imitation, repetition) "display a certain tension between 'oneness' and 'separate individuation"” (p. 335). $\mathrm{He}$ also discussed the critical role of similarities in our recognition as "they help us to leave the safe ground of known, labeled, categorized terms, and to expand our knowledge and language to newly discovered areas" (p. 342, italics added). Thus, similarity is what works in the middle of the same $<>$ non-same tension we undergo every day, and Sovran's discussion again suggests that the development is what happens as our non-sameness also brings about our similarity in time.

Looking at the emergence of the presentational self in conversation and writings considering the dynamics above, part of the background that constitutes this phenomenon is the repetition of similar activities in similar environments. In concrete terms, repeated reunions offer similar settings for children (e.g., talks during car rides, writing stories in a notebook). These similar settings include a variety of minor non-sameness (e.g., what they see from the car window, what the child ate before writing a story) and they give the meaning construction fluctuation in repetition, as I discussed using the metaphor of waves on the beach, in which a very high wave is occasionally seen (Chap. 3) (Fig. 8.1).

This is typically observable in the nikki of third- and fourth-grade children (Chap. 5). They often repeatedly write the same type of story describing what happened in a time sequence. In this repetition of writing in similar settings, they construct the meaning of their experiences in similar ways. However, within the amplitude of similarity, there sometimes appears an extension of meaning construction that marks a peak in the fluctuation. Although the mother-child conversation is more complex in its repetition because there are two participants engaging in mean-

Development of meaning (e.g., complexity) -> Achieved non-sameness of the children
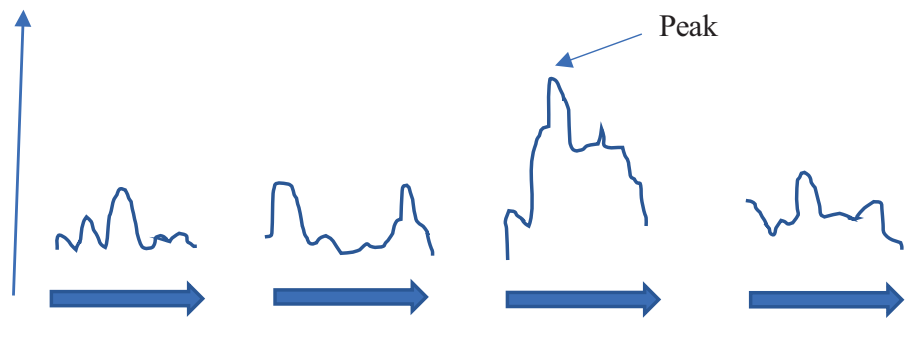

Repetition of the similar contexts in time.

Fig. 8.1 Development of meaning in repetition 
ing construction with their own experiences, a similar foundation for meaning construction exists in its repetition.

This suggests two types of similarity, or same $<>$ non-same tension, at work in the activities I have analyzed: one in the similarity of contexts and another in the similarity of children achieved in meaning construction. The episodes I picked up from massive amounts of data were typical ones at the extreme ends of fluctuation in everyday dialogue. This also shows the possibility of understanding development by looking at the repetition, fluctuation, and peaks that appear in them, and not relying on quantitative indices that often overlook such small changes by calculating average values.

\section{Our mind Emerges and Develops in the Similarity of Behaviors}

The perspective of seeking development within the tension of same $<>$ non-same appeared very early in the history of modern psychology. Baldwin (1892) discussed the emergence of volition in young children, focusing on the role of persistent imitation that appears when infants repeatedly try to grasp something, for example. In his framework, persistent imitation differs from simple imitation in two aspects: "a comparison of the first result produced by the child (movement, sound) with the suggesting image of "copy' imitate, i.e., deliberation" and "the outburst of this complex motor condition in a new reaction, accompanied in consciousness by the attainment of a monoideistic state (end) and the feeling of effort" (p. 286). This suggests that Baldwin believed the foundation of the emergence of our mental functioning lies in the repetition and the comparison of similar actions.

In the construction of developmental psychology in history, theoretical thinking after Baldwin often considered the opposition of same $<>$ non-same, which leads to the repetitive occurrence of similarity or difference, to be the foundation of development. This dialectic idea played an important role in Vygotsky's development of the concept of the zone of proximal development (Valsiner \& van der Veer, 2014). The concept of equilibration by Piaget (1985) also considered negation in the interaction between a subject and an object, or subsystems and total system, as its sources.

Baldwin's discussion also shares a common structure with what I have discussed here, although many differences in objects and approaches are also evident. Put simply, both approaches seek to find the mind in the repetition of similar actions-what Baldwin found is young children's "volition" to control their own actions, while I have discussed the self that becomes observable from the traces of repeated meaning construction. In other words, repetition of similar acts provides the space in which the individual mind develops. From this comparison, it may sound as though Baldwin discussed volition as a completely objective phenomenon, unlike my discussion that stressed the role of the observer who finds the self in meaning construction. However, here I point out the existence of Baldwin's own perspective, which attempted to find the function of mind in children's repeated movements and their reactions to them. In this aspect, Baldwin was also an observer who interpreted children's acts. 
The level of non-sameness that triggers a new starting point of fluctuation
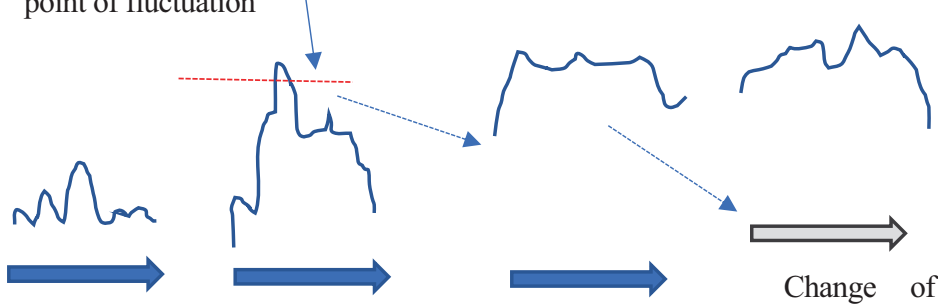

Change of the repeating contexts generated by the new pattern of conduct

Fig. 8.2 Construction of new types of fluctuation

This focus on similarity in repetition as a source of development of mind suggests the need to include how we behave over and over again in our daily lives. Although not clearly described in my inquiries, the discussions by Baldwin or Piaget suggest changes in such repetition can generate further, clearer changes in our own acts, as hypothetically depicted in Fig. 8.2. In this process, the peak in fluctuation works to set a new starting point that leads to another fluctuation, and this change also gradually creates the alteration of repeating contexts that enables another fluctuation. ${ }^{1}$ The repetition in our daily lives looks like reiterations of mundane, conventional conduct, but it has the potential to serve as the starting point for qualitatively different action. In other words, movements of data that are often considered errors, and either controlled or canceled in the accumulation of mass data, are actually what leads the development.

However, not only quantitative approaches to development but also many qualitative inquiries fail to pay attention to the repetition of everyday activities or the fluctuation of what is narrated in interviews, except for a few studies (e.g., Potter and Wetherell 1987) focusing on the instability of attitudes observable in interviews. This tendency shows psychology's basic orientation toward presupposing the stability of ourselves and trying to reveal development using one-time questions, including interviews for qualitative analysis. These studies miss an important presupposition of development.

\section{Conclusion: Spring Up in Repetition, Happen to Be Self}

The discussion in this short chapter added some elaboration of the same $<>$ nonsame tension that is involved in the foundational structure that promotes the meaning construction (Chap. 6). In clear contrast with another opposition, the visible $<>$

\footnotetext{
${ }^{1}$ This discussion is based on the discussion by Ujiie (1996) that inquired into the nature of development citing a variety of theories, including chaos theory with non-linearity, and many records of observation and interviews.
} 
invisible, which we often intentionally seek to control or construct, the dialectic tension concerning sameness is somewhat latent but indispensable in the process of development, as the theories that founded developmental psychology tell us.

This dialectic that actually appears as similarity works in two ways in relation to the meaning construction I analyzed to enable the emergence of the presentational self. One is the similarity of the contexts in which children re-construct their experiences, and sometimes their futures. The similarity of the environment provides repetition of meaning construction that constructs the non-sameness of children. Children constantly exist with non-sameness in relation to themselves in the past, and their meaning construction is the clarification of their non-sameness. However, somewhat contradictory, this is achieved within the range of similarity they maintain.

Under this half-restricted condition, meaning construction springs up again and again in the dialogical dynamics with others in different modalities: sometimes in reality (i.e., conversation) and sometimes presumed by children (i.e., nikki writing). In these activities, our orientation toward sameness can avoid the construction of non-sameness by saying or writing "Nothing new" or "Good as always," but there sometimes appears an upsurge that shows a clearer presentational self. In other words, some moves within the repetition of similar meaning constructions happen to be found as children's selves with uniqueness.

This perspective may befit the approach of a therapist more than a researcher. For example, Utsumi's (2013) inquiry as a clinical psychologist caring for children in homes for abused children describes several very brief but impressive moments in which children reveal contemplative comments about themselves despite broadranging aggression and emotional confusion. These are not necessarily related to the drastic changes in their conduct, but can be understood as events that constitute the therapist's understanding of the child as a whole. Such moments surely happen and can be important in therapeutic relationships, but these are not clarified by ordinary psychological methods.

The discussion here still does not predict when meaning construction will develop, but instead describes the very fundamental dynamics in which it occurs. Considering the process here including the dialectics of visible $<>$ invisible, both meaning construction and human development are better understood when we describe these together with their instability, from a subjective perspective that focuses on specific moments.

Open Access This chapter is licensed under the terms of the Creative Commons Attribution 4.0 International License (http://creativecommons.org/licenses/by/4.0/), which permits use, sharing, adaptation, distribution and reproduction in any medium or format, as long as you give appropriate credit to the original author(s) and the source, provide a link to the Creative Commons license and indicate if changes were made.

The images or other third party material in this chapter are included in the chapter's Creative Commons license, unless indicated otherwise in a credit line to the material. If material is not included in the chapter's Creative Commons license and your intended use is not permitted by statutory regulation or exceeds the permitted use, you will need to obtain permission directly from the copyright holder. 